\title{
Hidradenitis süppürativalı bir olgunun tedavisi
}

\author{
Treatment of a case of hidradenitis suppurativa
}

Halil Sağınç

\section{Özet}

Hidradenitis süppürativa apokrin salgı bezlerinde genellikle ağrılı, derin yerleşimli ve inflamatuvar lezyonlu kıl folliküllerinin tekrarlayan kronik inflamatuvar bir deri hastalığıdır. Hastalık aksiller, inguinal, perineal ve genital bölgelerde görülür. Radyoterapi dirençli hastalıkta tedavi seçeneğidir. Burada diğer tedavilere dirençli radyoterapi ile lezyonlarında belirgin gerileme olan hidradenitis süppürativalı bir olgu sunduk. Olgu 47 yaşında üç yıldır hidradenitis süppürativa tanılı erkek hastaydı. Bilateral aksiller bölgesinde ağrılı, akıntılı Hurley 3. evre nodülokistik lezyonlara sahipti. Hastalık hastanın yaşam kalitesini bozmuştu. Olgu düzenli olarak alkol ve sigara kullanıyordu. Olgu 103 kilogram, vücut kitle indeksi 31,1 kg/m²'ydi. Bilateral aksiller bölgeye 2,5 Gy/gün toplam 7,5 Gy konformal radyoterapi uyguladık. Radyoterapiden üç ay sonraki muayenesinde semptomlar belirgin azaldı. Nodüller ve akıntılı lezyonlar belirgin iyileşti.

Anahtar kelimeler:Hidradenitis süppürativa, eksternal radyoterapi, inflamatuvar deri hastalıkları.

Sağınç H. Hidradenitis süppürativalı bir olgunun tedavisi. Pam Tıp Derg 2021;14:285-287.

\begin{abstract}
Hidradenitis suppurativa is a chronic, recurrent, inflammatory skin disease of the hair follicles that presents with painful, deep-seated lesions in apocrine glands. The disease is seen in the axillary, inguinal, perineal and, genital areas. Radiation therapy is a successful treatment option for resistant disease. We presented here a case of hidradenitis suppurativa of whom significant regression of lesions with radiotherapy treatment-resistant to other treatments. A 47-year-old male has been diagnosed with hidradenitis suppurativa for three years. The case had Hurley stage 3 painful, discharging nodulocystic lesions in the bilateral axillary region. The patient's quality of life was getting worse due to the disease. The patient was using alcohol and cigarette regularly. The case was 103 kilograms, and the body mass index was $31.1 \mathrm{~kg} / \mathrm{m}^{2}$. The case received total doses of $7.5 \mathrm{~Gy}$ at $2.5 \mathrm{~Gy}$ per fraction with conformal radiotherapy to bilateral axillary regions. The patient's axillary symptoms reduced significantly after three months of radiation treatment. The discharging nodulocystic lesions were significantly improved.
\end{abstract}

Key words:Hidradenitis suppurativa, external radiotherapy, dermal inflammatory diseases.

Saginc H. Treatment of a case of hidradenitis suppurativa. Pam Med J 2021;14:285-287.

\section{Giriş}

Hidradenitis süppürativa, vücudun apokrin bezlerinde epidermisin rekürren, derin yerleşimli ve inflamatuvar lezyonlarla ortaya çıkan kronik inflamatuvar bir deri hastalığıdır. Skar, pürülan akıntı ve sinus formasyonu gibi bulgular ile seyreder [1]. İnflamatuvar ve noninflamatuvar ağrılı tekrarlayan lezyonlar, aksilla, inguinal, perineal ve genital bölgeler gibi vücudun belirli bölgelerinde görülür. Hastalık obezite, artropati, inflamatuvar bağırsak hastalığı ve skuamöz hücre kanseri ile ilişkilidir [2]. Hastalık genellikle ergenlikten sonra başlar. En yaygın olarak üçüncü dekatta görülür. Yaşılıkla birlikte kronikleşir. Pilo-sebose-apokrin glandın hasara uğraması, sekonder inflamasyonu, enfeksiyonu ve bitişik deri altı dokuya uzanımı ile ortaya çıkan hastalık, yaşam kalitesinin bozulmasına yol açar. Hastalık kadınlarda erkeklerden daha yaygındır. Sigara ve obezite hastalığın semptomlarını ağırlaştırır. Hastalığın evresine bağlı olarak tedavi değişir. Erken nodüler lezyonlar akut evrede antibiyotiklerle tedavi edilirken uzun süreli antibiyotikler, çinko tuzları idame tedavisi olarak kullanılırlar. Lezyonları ağır seyreden olgularda anti-TNF, sistemik steroidler, östrojenler, antiandrojenler, retinoidler kullanılır. Drenajlı veya drenajsız insizyonlar lokal apseler için kullanılırken lokal tekrarlayan 
drenaj sinüsleri için sınırlı eksizyonlar kullanılır. Flep ve greftli total geniş eksizyonlar ileri evre hastalık için küratif tedavi için kullanılır [3, 4]. Konvansiyonel tedavilere ve cerrahi tedavilere dirençli olgularda eksternal radyoterapi başarılı bir tedavi yöntemidir [5].

\section{Olgu}

Olgumuz 47 yaşında 3 yıldır hidradenitis süppürativa tedavisi gören, 103 kilogram, vücut kitle indeksi31,1 kg $/ \mathrm{m}^{2}$ olan erkek olguydu. Hasta kendisine önerilen sistemik izotretinoin, aksiller flep operasyonunu kabul etmemişti. Bu nedenle hastaya radyoterapi yapılması planlandı. Sağ ve sol inguinal bölge lezyonlar Hurley evre 2'ydi. Olgunun yaşam kalitesi bilateral aksilladaki lezyonlar nedeniyle kötüydü. Düzenli olarak alkol ve sigara kullanıyordu. Radyoterapi öncesi bilateral aksiller bölgelerde ağrılı, akıntılı, Hurley 3. evre nodüler lezyonlar vardı (Şekil 1a). Aksiller lezyonlar derin yerleşimli olduğundan olguya her iki aksillaya elektron radyoterapi planı yerine foton ile konformal radyoterapi planı kabul edilerek 3 fraksiyon ile 2,5 Gy/gün total 7,5 Gy doz radyoterapi tedavisi uygulandı. Tedaviden üç ay sonra olgunun aksiller lezyonlarında regresyon ve semptomlarında yüzde 80 oranında bir azalma görüldü (Şekil 1b). Tedaviden iki yıl sonra sağ aksilla radyoterapi aldığı bölgenin dışında iyileşen lezyonların üst kısmında yeni tek lezyon geliştiği görüldü. Sol aksillada ise lezyonlarda yüzde 80 iyileşme devam etmekteydi.

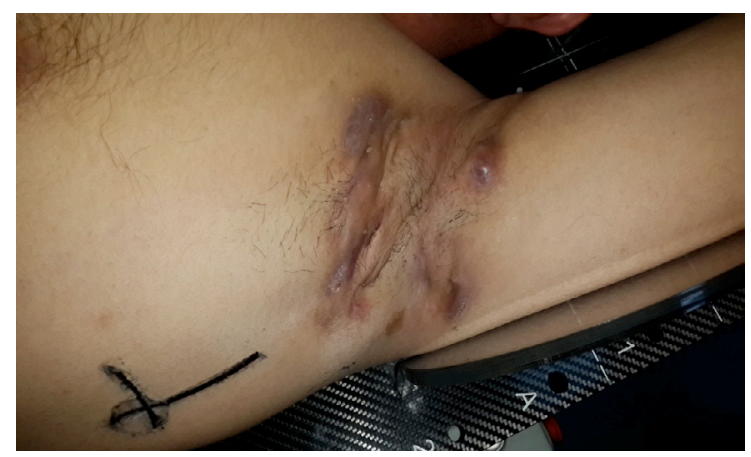

Şekil 1a. Hidradenitis süppürativalı olgunun radyoterapi öncesi sol aksiller alandaki lezyonları

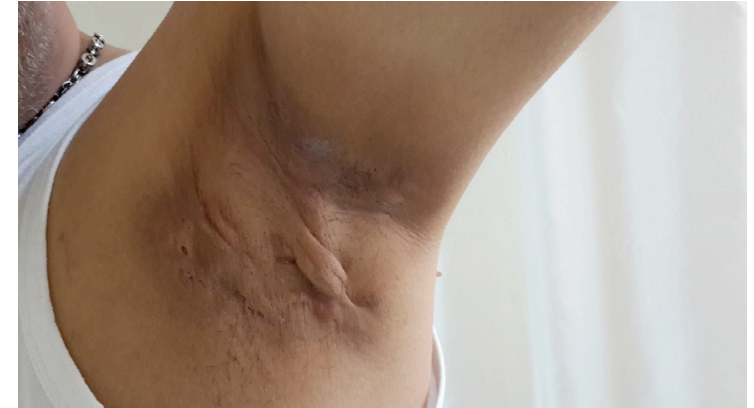

Şekil 1b. Hidradenitis süppürativalı olgunun radyoterapiden 3 ay sonra tedaviye yanıtlı sol aksillar alandaki lezyonları

\section{Tartışma}

Konformal radyoterapi ile tedavi edilen hidroadenitis süppürativa tanılı olgumuzda radyoterapiden sonra lezyonlarda belirgin regresyon ve semptomlarda yüzde 80 oranında yanıt elde edildi. Sağ ve sol aksillada radyoterapi aldığı bölgede tekrarlama gözükmedi. Sadece radyoterapiden bir yıl sonra sağ aksilla radyoterapi aldığı bölgenin dışında tek lezyon gelişti. Literatürü incelediğimizde yapılan dirençli olgularda radyoterapi ile ilgili birkaç çalışma vardır. Fröhlich ve ark.'nın [6] çalışmasında diğer tedavilere yanıt vermeyen 231 olgu radyoterapi ile tedavi edilmiştir. Tedavinin sonunda olguların yüzde 38 'inde tam bir semptomatik yanıt olduğu görülmüştür. İki olguda ise tedaviye hiç yanıt görülmemiştir. Bir kadın olgulu başka bir çalışmada radyoterapi ile tedavi edilmiştir. Olguda radyoterapiye bağı akut yan etki gözlenmediği görülmüştür. Radyoterapiden iki hafta sonra semptomlarda tam bir iyileşme olduğu görülmüştür. Olgu az yağlı bir diyet ile bir buçuk yıl sonunda 45 kilogram kaybetmiş ve iki buçuk yılda nüks lezyonları görülmemiştir [5]. Patel ve ark.'nın beş olgulu çalışmasında refrakter hidradenitis süppürativa tedavisinde olgularda tam yanıt görülmemişken, lezyonların $\% 53$ 'ünde kısmi bir yanıt sağlanmıştır. Aksillada $\% 100$, gluteal $\% 67$ ve inguinal bölgelerdeki lezyonlar \%50 yanıt varken perineal lezyonlarda ise hiç yanıt alınmamıştır [7]. Bizim olgumuzun takiplerinde kilo vermediği görüldü ve sigara ve alkol kullanımı sorgulandığında devam ettiği görüldü. Olgumuzun tedavi sonuçları literatür ile uyumluydu. Olguda aksiller lezyonlarda ve semptomlarında belirgin bir iyileşme olduğu görüldü. İkinci yılda sağ aksillada radyoterapi aldığı bölgenin dışında iyileşen lezyonların üstünde yeni tek lezyon geliştiği görüldü. 
Sigarayı ve alkolü bırakmak, düzenli yürüyüş ve egzersiz yapmak, diğer tedavilere yanıt vermeyen olgularda radyoterapi uygulamak hidradenitis süppürativa tedavisinde semptomları ve lezyonları iyileştirir. Radyoterapi diğer tedavilere dirençli rekürren hidradenitis süppürativa için başarılı bir tedavi seçeneğidir.

Çıkar ilişkisi: Yazar çıkar ilişkisi olmadığını beyan eder.

\section{Kaynaklar}

1. Mooij JE, Van't OL, Leenarts MF, Mekkes JR. Treatment options in severe hidradenitis suppurativa. Ned Tijdschr Geneeskd 2011;155:1912.

2. Dini V, Oranges T, Rotella L, Romanelli M. Hidradenitis suppurativa and wound management. Int J Low Extrem Wounds 2015;14:236-244. https://doi. org/10.1177/1534734615598890

3. Revuz J. Hidradenitis suppurativa. J Eur Acad of Dermatol Venereol 2009;23:985-998. https://doi. org/10.1111/j.1468-3083.2009.03356.x

4. Jemec GB. Clinical practice. Hidradenitis suppurativa. N Engl J Med 2012;366:158-164. https://doi. org/10.1056/NEJMcp1014163

5. Trombetta M, Werts ED, Parda D. The role of radiotherapy in the treatment of hidradenitis suppurativa: case report and review of the literature. Dermatol Online J 2010;16:16.

6. Fröhlich D, Baaske D, Glatzel M. Radiotherapy of hidradenitis suppurativa-still valid today?. Strahlenther Onkol 2000;176:286-289.

7. Patel S. H, Robbins J. R, Hamzavi I, Radiation Therapy for Chronic Hidradenitis Suppurativa. J Nucl Med Radiat Ther 2013;4:1.

Hasta onamı: Yazılı hasta onamı hastadan alınmıştır. 